\title{
Teacher Training in Sub-Sahara Africa
}

The Imfundo Initiative

\author{
Michelle Selinger \\ Cisco Systems, 9 New Square Park, Bedfont Lakes, Feltham, TW14 8HA, UK \\ mselinge@cisco.com
}

Keywords: developing countries, distance learning, in-service training, integration of ICT, teacher education

\begin{abstract}
Imfundo was set up in May to consider ways in which ICT could be used in education, particularly teacher education, in developing countries with a focus on sub-Saharan Africa. It has three objectives. First, the establishment of pilot initiatives to find out what the main issues are in using ICT for teacher training in the developing world. Then development of a ResourceBank, a repository for private sector commitment of project management skills and resources in kind or at cost; and the KnowledgeBank, a web site of information and discussion about ICT use in education in developing countries.
\end{abstract}

\section{BACKGROUND TO THE IMFUNDO INITIATIVE}

The Imfundo initiative was set up in May 2000 in response to the UK Prime Minister's millennium initiative for education. Based in the Department of International Development (DFID) in London, Imfundo's remit was to consider ways in which ICT could be used in education in developing countries with a focus on teacher education, thus providing one way for the UK to support the International Development Targets for universal primary education by 2015 . The main focus was to be in subSaharan Africa, which had some of the worst statistics on basic education. The initiative team hsd six months to explore and report on this objective; they had to identify and develop a small number of pilot initiatives and to conduct a feasibility study into how this initiative could be taken forward. 
They also had to consider the involvement of the private sector, and from the outset included three secondees from industry on the seven-strong initiative team. Imfundo is currently developing five pilot initiatives in three countries.

Imfundo was also asked to consider sustainability with a focus on involving the private sector and developing public-private partnerships. Many companies are keen to contribute to development initiatives, yet in order to avoid a plethora of well-intentioned projects that are unconnected and divorced from Government policy, it is important to co-ordinate efforts into a sector wide strategy. Imfundo can identify and scope such initiatives in liaison with DFID and other donor agencies, and then draw in private sector support as appropriate. To this end the team have developed the ResourceBank, a repository of private sector commitment from which to draw down resources for initiatives. The nature of this support will be in the form of project management expertise, hardware, software, technical expertise and other resources. It is not the intention to ask companies for donations: expertise and resources are what is required. The involvement of local private sector is as important as involving international companies, and indeed, could be crucial to ensure that initiatives are sustainable beyond the initial funding stage.

At the start of the initiative it was important to understand and have information about the use of ICT in education and in teacher training; the current infrastructure in countries, including access and costs of telecommunications, information technology and power; and background to the reasons why children did not go to school. Gathering such information takes time. Therefore a KnowledgeBank was established and published on the Imfundo web site (www.imfundo.org) to provide a central repository to inform the team and others, thus helping anyone involved in related initiatives. An electronic forum in which participants are encouraged to comment on KnowledgeBank papers, and share insights and information has supplemented this knowledge sharing. Currently over 200 participants world-wide are taking part in this active forum.

\section{TRAINING TEACHERS: THE ISSUES}

HIV/AIDS and civil war have decimated the teaching population in many countries in sub-Sahara Africa. There is little capacity to train the increasing number of teachers needed. 113 million children are currently out of school, 97 per cent of them in the less developed regions of the world and 60 per cent of them girls (UNESCO 2000). An international development target is to to achieve universal primary education by 2015 , and to eliminate the gender disparity in primary and secondary education by 2005 . 
While some regions, notably Latin America, the Caribbean and East Asia, are on course to achieving universal access to primary education, others are slipping behind. The problem is particularly marked in subSaharan Africa, where the number of children not in school is increasing. Of the 113 million children out of school in 1998, 42 million lived in subSaharan Africa; of these, $56 \%$ were girls. When children do go to school, the quality of education is poor as many teachers have received inadequate training and class sizes are large. The pupil teacher ratio varies considerably across sub-Saharan Africa, and exceeds 50 in many countries. In Central and West Africa, the median class size is 52 .

International development targets mention the quality of education, but do not give it sufficient emphasis. Nearly two thirds of children who go to school in sub-Saharan Africa leave school illiterate. About half of teachers in developing countries are unqualified in terms of their own country's formal standards for teachers' education. Teaching methods are often antiquated with a focus on rote learning and little opportunity to try new teaching strategies with group work or learner-centred approaches. Many countries in provide little or no in-service professional development support for teachers.

\section{A CASE STUDY}

In one country ravaged by civil war, the shortfall of teachers was made up by a large number of unqualified teachers mostly comprising people who have no more than secondary education themselves, and a few not having even completed that. An emergency short training programme on teaching methodologies was mounted in programmes of up to five days, but this was inadequate to meet their full training needs. This measure was less than sufficient for teachers to gain appropriate skills, but it was all that was possible when the priority was to rehabilitate and refurbish schools so that children could return to school with sufficient teachers to teach them.

Therefore there was a pressing need to develop both content knowledge and professional capability. In addition the number of secondary schools is rapidly increasing. Class size is usually around 40-50 but in some schools it can be nearer $70.16 \%$ of children go to secondary school and this number is intended to rise to $20 \%$. Teachers cannot be taken out of school in large numbers for the extensive training programme that is required. In reality this should be, a three year, full-time training programme and equivalent to a pre-service programme in both subject knowledge and pedagogy. Removing teachers from the classroom for this length of time is unworkable. Teacher training institutions would have neither the physical capacity nor the human resources to train such large numbers. So distance education is the only 
feasible alternative, with teachers training while still teaching. The benefits would be to keep them in classrooms while undergoing training so school attendance targets could be maintained, allowing teachers to put new ideas into practice so integrating theory and practice. A lesser issue, was the relative costs of distance training.

Research on distance education in developed countries is extensive, but there is relatively little covering the developing world. Hilary Perraton comments on distance education in developing countries, including the relative costs of distance education and classroom based teaching.

"Distance education has particular strengths where it is used to support extension agents so that a multiplier effect comes into play. Education out of school, whether for adults or through alternative secondary schools, has lower costs than conventional education and would probably not exist unless it did so. In many cases its modest costs are matched by modest success; poor completion and pass rates mean that its costs per successful student tend to compare much less favourably with conventional alternatives. Teacher education has a potential multiplier effect and high motivation levels, for teachers expecting promotion, and has brought high success rates with competitive costs per graduate." (Perraton 2000, p1)

Butcher (2000) also considers the financial issues, but additionally cites the top down approach of initiatives being a cause of failure. Ensuring buyin from those who will have to implement and use the systems is paramount. Despite a number of issues in developing distance learning programmes, there is evidence that a number of models are being used across the developing world, many with older technologies like radio and video as well as some trialling new technologies (Capper 2000, Fontaine 2000).

In this country there were problems with part-time learning. Historically teachers were paid for attending training courses, but the country is now unable to afford any extra payments; teachers will receive training free of charge, but with no funds to help them to attend. With so many teachers requiring this training, it is hoped that for several years there will be a steady stream of teachers willing to support themselves, with the only reward being higher salaries on completion. A number of initiatives including visits to head teachers and local education officers, and identification of training centres in regional centres that had telephone access and an adequate power supply. There are plans to staff these centres with a well-qualified teacher as a tutor supported by an administrative assistant.

Head teachers have been made aware of the need to give teachers undergoing the training extra time to study by, for example, allocating them smaller workloads, exempting them from evening and weekend duties, and 
granting loans to purchase transport (bicycles or motorcycles) to support their travel to training centres. Part-time study for further qualification is becoming an accepted aspect of further education in this country so there is a firm belief that there will be heavy demand for these courses.

Another problem the country faces is the capacity to develop distance learning resources. The initial costs of setting up such programmes are high compared to traditional courses, and there is lack of expertise in developing distance learning materials. This problem has been solved through donor funding to bring in distance learning expertise and a number of subject experts from other countries for a fixed time period to develop the materials and to train existing staff at the teacher training institution.

As in many developing countries the costs of books and other resources is high, and maintaining up to date libraries is expensive. Postal deliveries are unreliable or take a long time, so the exchange of assignments and materials would be slow and would also make student progress slow. Tutors based in regional centres would have to be expert in all secondary subject areas if they were required to support all students, and any extra support from the central teacher training institution would be restricted to phone calls and post. Telephone lines are limited with very few lines available outside the country's capital.

\subsection{ICT as a solution}

A range of new and old technologies could help. Internet connectivity in each of the regional centres would provide teachers in training and the regional tutors with fast access to the central teacher training institution. Here subject specialists could respond in electronic discussion forums to questions posted by tutors or trainees; extra materials could be supplied digitally for printing at the local centre; and some interactive internet based resources could also be accessed by teachers after school and weekends, at times to suit them. Video materials could be sent via a satellite link or on videocassette; and up to date resources could also be accessed through the Internet.

The successful use of the Internet is teacher training is reported in a number of international initiatives (see Perraton 2000). In Africa it has been tried successfully in townships in South Africa through the ShoMa initiative in South Africa ((ShoMa undated). Together with the National and Provincial Education Departments ShoMa has developed a professional development curriculum for teachers. Multimedia materials are delivered digitally via satellite. ShoMa involves a three stage process in a three hour weekly course. In the first part of the process, teachers are actively engaged in learning about various aspects of the new outcomes based education 
programme that has been recently introduced into South African schools. Short video excerpts are downloaded via satellite and viewed followed by a discussion that is prompted and guided through the questions posed on screen. The second stage involves the Internet in which teachers individually explore the concepts discussed in the video. Through this ShoMa staff believe teachers are able to determine their own needs in terms of theory and interest. Relevant aspects of the video have been digitised to support the written component and to integrate the learning experience.

Teachers interact with the Internet based materials and the data they enter is kept on a database that can be printed out later and added to the teacher's portfolio as evidence of their developing understanding and for assessment purposes. The final stage is considered to be the most important aspect of the learning experience. In this stage teachers work collaboratively in groups of approximately six to develop their lesson plans for the following week. By making use of facilitators from the Education Department or a 'leader' educator, ShoMa helps teachers to share experiences and develop lesson ideas through the application of their new knowledge.

\subsection{Details of the training}

It is planned to integrate a modified version of the ShoMa materials into the programme, and Imfundo have facilitated personnel from ShoMa to work with the teacher training institution. The training will start at diploma level and develop to degree level as resources become available and teachers become accustomed to improving their skills through distance learning. Modules will develop knowledge in two subjects and in pedagogical skills, and will be based on the new four year full- time initial teacher training course that is currently in its third year of operation at the teacher training institution.

The original plan was to train 1000 students per year over 5 years but after further discussions it has been decided to roll out the programme more slowly opening two centres in 2001, training between 50 and 100 teachers in each location. The training centres will come on stream in a phased progression and will be open six days a week, and there will be organised weekend and evening sessions as well as opportunities for teachers to drop in and use the facilities. Residential summer schools will be run of approximately two to three weeks duration in four identified secondary school locations in each region. 


\subsection{Sustainability}

Technology is expensive but in developed countries the cost of maintaining and updating ICT is also of major concern. Parts as well as PCs carry high tariff charges. In developing countries issues of sustainability have to be addressed, not only in terms of the maintenance and renewal of equipment, but also in the provision of spare parts, qualified engineers and trained personnel to troubleshoot minor issues and train users. Many development initiatives have failed once funding has ceased because long term sustainability was not taken into account. The ResourceBank is one way in which sustainability can be addressed. The international private sector are being asked to give support in terms of reduced costs for or donations of equipment, software etc, or to provide personnel to train local people or to initiative manage the establishment of the centres. Local private companies have been invited to make use of the spare capacity of teacher training centres to run basic ICT skills and adult literacy courses, and small businesses are to be encouraged to make use of the facilities for their own work at a small charge. In other words these teacher training centres will aim to double up as multi-purpose community centres.

\section{IS ICT APPROPRIATE?}

There is not a straight choice between using new and old technologies in distance education. For example, where teachers are supported through resource centres, it would be possible to use radio and text for much the content, with other resource centres to provide opportunities for interaction and support. Radio is pervasive in developing countries. In their research Imfundo did not uncover any teacher education programme that combined new and old technology.

Distance education, whether or not technology enhanced, is cost effective only if it is on a reasonably large scale. Thus while it may be cost effective in Nigeria or South Africa, it may not be in smaller countries such as Gambia. Therefore Imfundo intends to undertake further work on the opportunities for regional initiatives to share technology, curriculum and infrastructure across countries. For example, it is cheaper to adapt curriculum material made in a neighbouring country than it is to start from scratch; the adaptation of the ShoMa materials is one model being trialled. 


\section{THE FUTURE OF IMFUNDO}

Imfundo has reached the end of its first phase. The second phase started January 2001, is a five year initiative to work in at least five more countries in sub-Sahara Africa with a new team leader and two advisers in place. They will be supported by DFID reporting to the Africa Economic and Policy Development Unit, and working closely with country desks and the education department. The new team will continue to maintain the focus on teacher training and professional development, and on educational management issues. Imfundo are currently in negotiation with other donors who are also focused on ICT in education, and thus continuing to ensure that development initiatives are coordinated and sustainable.

\section{REFERENCES}

Butcher, N. (2000) Distance education in developing countries. The Imfundo KnowledgeBank [http://www.imfundo.org/butcherthree/contents.htm] 5.8.2001

Capper, J. (2000) Teacher training and technology: an overview of case studies and lessons learned. TechKnowLogia, 2 (6), pp. 17-19 [www.techknowlogia.org].

Fontaine, M. (2000) Teacher training with technology: Experience in five country programs. TechKnowLogia, 2 (6), pp. 69-71 [www.techknowlogia.org].

Perraton, H. (2000) Teaching the teachers. The Imfundo KnowledgeBank. [http://www.imfundo.org/Hilaryfive/contents.htm] 5.8.2001.

ShoMa (undated) ShoMa Education Foundation: professional development initiative. [http://www.shoma.org.za] 5.8.2001.

UNESCO (2000) Education for all 2000 Assessment: Statistical document. [http://www2.unesco.org/wef/en-docs/findings/efastatdoc.pdf] 5.8.2001.

\section{BIOGRAPHY}

Michelle Selinger is an Education Specialist at Cisco Systems and Senior Visiting Research Fellow at the Open University's Institute of Educational Technology. Her current research interests are in elearning and changing pedagogies in ICT environments. 